sehr vielen dieser Essenzen war überdiefs die Aehnlichkeit mit den angegebenen Aromen aufserst zweifelhaft.

Dic Anwendung der organischen Chemie auf die Parfümerie ist noch neu; und es läfst sich erwarten, dals eine genauere Durchsicht der bekannten und täglich bekannt werdenden Aether oder ätherähnlichen Verbindungen zu weiteren Ergebnissen führen wird. Die interessanten Capryläther, welche Herr Bou is neuerdings enldeckt hat, sind vielfach durch einen äufserst aromatischen Geruch ausgezeichnet - das essigsaure Capryloxyd z. B. besilzt einen ebenso intensiven als angenchmen Geruch - , und versprechen, wenn sic anders sich in gröfserer Menge werden darslellen lassen, der Parfümerie neue Malerialien zu liefern.

Chemische Untersuchung der Schwefelquelle zu Weilbach im Herzogthum Nassau;

\title{
von $\boldsymbol{H}$. Will.
}

Die qualitalive Analyse des Wassers ergab folgende Bestandtheile :

Basen

Kali

Natron

Lithion

Strontian (Spur)

Kalk

Magnesia

Eisenoxydul

Manganoxydul (Spur)

Thonerde

Ammoniak (Spur)
Säuren oder sio vertretende Körper Schwefel (als Schwefelnatrium) Schwefelsäure

Kohlensäure

Phosphorsäure

Chlor

Brom

$\left.\begin{array}{l}\text { Jod } \\ \text { Fluor }\end{array}\right\}$ Spuren

Kieselerde

Organische Subslanz. 
Das vollkommen klare, nur wenig perlende Wasser setzt beim Einkochen alle erdigen Salze ab und reagirt dann slark altralisch. Der lösliche Theil des eingekochten Wassers enthält dann nur Salze von Kali, Natron und Lithion nebst organischer Substanz. Das Jodnalrium, der kohlensaure Strontian und Fluorcalcium wurden in dem löslichen und unlöslichen Theil der Mutterlauge nachgewiesen, welche Herr Medicinalassessor $\mathrm{J}$ u ng von Hochheim mit grofser Sorgfalt bereitete.

Verdampft man den lüslichen Theil der Mutterlauge nach der Neutralisation mit Salzsäure zur 'Trockne, zieht den Rückstand mit Alkohol aus und behandelt den verdampften alkoholischen Auszug alsdann mit einer Mischung von wasserfreiem Aether und Alkohol, so löst sich Chlorlithium auf, erkennbar an der purpurrothen Flamme des darüber entzündeten Alkohols. Schültelt man die Multerlauge mit Chlorwasser und Aether, so färbt sich letzterer von aufgenommenem Brom gelb. Das Jod, welches nur in selır geringer Menge vorhanden ist, wurde nachgewiesen, indem eine grölsere Menge der Multerlauge zur 'Trockne verdampft, der Rückstand mit Alkohol ausgezogen, der Auszug noch einmal verdampft und wieder mit Alkohol behandelt wurde. Diese Auflösung zeigte, nach der Entfernung des Alkohols, mit Stärkmehlkleister und Salpetersäure die bekannte Jodreaction. - Aus mehreren mit einer litrirten Jodlösung angestellten Bestimmungen des Schwefelnatriumgehaltes ergab sich, dafs das in Krügen versendete Wasser nahezu ${ }_{6}^{5}$ seines ursprünglichen Gehalts an Schwefelnatrium verloren hatle.

Die in gewöhnlicher Weise ausgeführte quantitalive Analyse gab die folgenden Resultate : 
a) In 1000 Theilen :

Kohlensaures Natron - . 0,33005

Chlornatrium . . . . 0,28674

Bromnatrium . . . . 0,00066

Schwefelnatrium . . . 0,01654

Schwefelsaures Kali . . 0,03740

Chlorkalium . . . . 0,02422

Kohlensaures Lillion . . 0,00670

Schwefel-

wasserstoff

Kohlensaurer Kalk . . $\mathbf{0 , 2 5 6 5 1}$

Kohlensaure Magnesia . $\mathbf{0 , 2 1 6 3 3}$

Kohlensaures Eisenoxydul 0,00205

Phosphorsaure Thonerde $\mathbf{0 , 0 0 1 1 9}$

Kieselerde . . . . . 0,01585

Organische Substanz . • 0,06368

1,25792 .

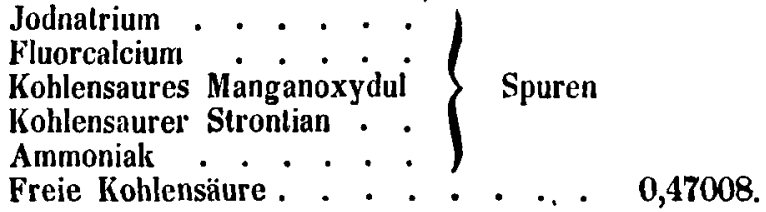

Ein Liter Wasser enthält bei der Temperalur der Quelle (130,72 C.) 248 CC. kohlensaures Gas.

Ein Liler Wasser enthält (wenn man den Schwefel des Schwefelnatriums auf Schwefelwasserstoffgas berechnet) bei der Temperatur der Quelle $\left(13^{\circ}, 72\right.$ C. $) 4,8$ CC. Schwefelwasserstoffgas.

b) In einem Pfunde $=16$ Unzen $=7680$ Gran :

In Granen

Kohlensaures Natron . . 2,5347

Chlornatrium . . . . 2,2021

Bromnatrium . . . . 0,0050

Schwefelnatrium . . . 0,1270

Schwefelsaures Kali . . 0,2872

Chlorkalium . . . . . 0,1858

Kohlensaures Lithion . . $\mathbf{0 , 0 5 1 4}$

Kohlensaurer Kalk . . . 1,9699

Kohlensaure Magnesia . 1,6614

Kohlensaures Eisenoxydul $\mathbf{0 , 0 1 5 7}$

Phosphorsaure Thonerde . 0,0091

Kieselerde . . . . . 0,1217

Organische Substanz . . 0,4890

9,6600 . 


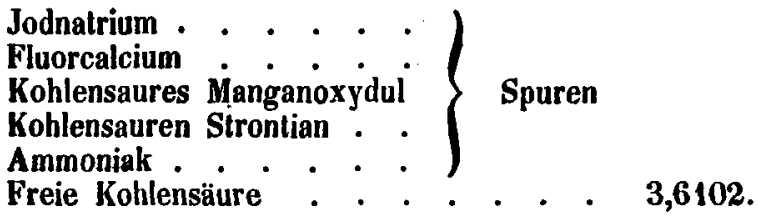

1 Pfund Wasser (=16 Unzen $=32$ Cub. - Zoll) enthält bei der Temperatur der Quelle $\left(13^{0}, 7\right.$ C.) kohlensaures Gas 7,93 Cub. - Zoll.

Ueber einige Producte der Einwirkung von Salpetersäure auf Citraconsäure;

$$
\text { von S. Baup *). }
$$

Gottlieb**) hat vor Kurzem eine erste Abhandlung über die isomeren Säuren veröffentlicht, in welcher er eine neue Säure beschreibt, die sich bei der Einwirkung von selir schwacher Salpetersäure auf Citraconsäure bildet; concentrirte Salpetersäure ergab ihm mehrere andere Producte, welche er später genauer beschreiben will.

Ich habe mich mit diesem Gegenstande schon vor mehreren Jahren beschäftigt, wo ich die Einwirkung der Salpelersäure auf mehrere organische Säuren untersuchte; ich halte erkannt, dafs die mit dem vierfachen Gewicht Wasser verdünnte Salpetersäure die Citraconsäure in eine neue Säure umwandelt, welche mit dieser isomer ist; dafs hingegen die concentrirte Salpetersüure eine selur energische Einwirkung auf die Citraconsäure ausübt und dabei unter andern Producten eine ölige Flüssigkeit giebt, aus

7) Ann. ch. phys. [3] XXXIII, 192.

**) Diese Annalen LXXVII, 265. 